\title{
Dopamine $\beta$-hydroxylase and p73 expression during aging and ventricular dilation in the cerebrospinal fluid and circumventricular organs of SHR rats
}

Emilia Ma Carmona-Calero*1,2, Ibrahim Gonzalez-Marrero1,2, Paloma Fernández-Rodríguez ${ }^{2}$, Herminia Perez-Gonzalez ${ }^{1}$, Juan M Gonzalez-Toledo ${ }^{1}$, Leandro Castañeyra-Ruiz ${ }^{2}$, Agustin CastañeyraRuiz ${ }^{1}$, Juan M Troyano ${ }^{1}$, Dionisio M Garcia ${ }^{1}$ and Agustín CastañeyraPerdomo ${ }^{1,2}$

Address: ${ }^{1}$ Departamento de Anatomía, Facultad de Medicina, Universidad de La Laguna, Tenerife, Islas Canarias, Spain and ${ }^{2}$ Departamento de
Biotecnología, Instituto de Investigación y Ciencias de Puerto del Rosario 35600, Fuerteventura, Spain
Email: Emilia Ma Carmona-Calero* - ecarmona@ull.es
${ }^{*}$ Corresponding author

from 50th Annual Meeting of the Society for Research into Hydrocephalus and Spina Bifida Cambridge, UK. 30 August - 2 September 2006

Published: 21 December 2006

Cerebrospinal Fluid Research 2006, 3(SuppI I):S6I doi:I0.1 186/I743-8454-3-SI-S6I

(c) 2006 Ma Carmona-Calero et al; licensee BioMed Central Ltd.

\section{Background}

It has been reported that spontaneously hypertensive rats (SHR) show ventricular dilation variations and changes in CSF proteins. The organum vasculosum of the lamina terminalis (OVLT) and the subfornical organ (SFO) are circumventricular organs located in the third ventricle, which are rich in neuropeptides such as angiotensin II and catecholamines. The SFO has connections with the brain regions involved in the central regulation of blood pressure and cardiovascular function. p73 is present in developing neurons as a truncated isoform whose levels decrease dramatically during sympathetic neuron apoptosis after nerve growth factor (NGF) withdrawal. Therefore, p73 is necessary for the survival and long-term maintenance of CNS neurons. The purpose of the present work is to study the dopamine beta-hydroxylase (DBH) and p73 expression in the SCO, the OVLT and the SFO and their variations in ventricular dilatation and arterial hypertension.

\section{Materials and methods}

Brains and cerebrospinal fluid (CSF) from control WistarKyoto rats (WKY) and spontaneously hydrocephalus rats (SHR) were used. The paraffin section containing the SCO, OVLT and SFO were immunohistochemically processed with anti-DBH and anti-p73. DBH and p73 band were identified in the CSF and circumventricular organ extract by western blot

\section{Results}

The SHR of 6 and 12 months of age showed a greater increase in ventricle size than those of normal sized WKY rats. In the electrophoretic study, we detected the presence of five protein bands: $141,117,48,43,39 \mathrm{kDa}$ in the CSF of the SHR rats, that were scarcely present in the CSF of the WKY rats. We also found that DBH was lower in the SFO of the hypertensive rats than in the WKY rats, and p73 expression was higher in the SFO of the hypertensive rats than in the WKY rats. While p73 was heavily expressed in the SCO and OVLT of the WKY rats this was scarce in the SCO and OVLT of the SHR rats. The SFO extract bands were also marked with anti-DBH and anti-p73 and the 
intensity of the reaction was higher in SHR than in the WKY rats.

\section{Conclusion}

The present results and the fact that the deltaNp73 is necessary for the survival of sympathetic neurons, would indicate that p73 is an essential survival protein in CNS catecholaminergic neurons, therefore there could be a relationship between p73, DBH and these cerebral centres involved in cardiovascular regulation.

Publish with Bio Med Central and every scientist can read your work free of charge

"BioMed Central will be the most significant development for disseminating the results of biomedical research in our lifetime. " Sir Paul Nurse, Cancer Research UK

Your research papers will be:

- available free of charge to the entire biomedical community

- peer reviewed and published immediately upon acceptance

- cited in PubMed and archived on PubMed Central

- yours - you keep the copyright

Submit your manuscript here:

http://www.biomedcentral.com/info/publishing_adv.asp 